\title{
Gas-Liquid Flow Regimes in Horizontal Annulus
}

\section{Edem Nsefik Eyo, Liyun Lao*}

Geo-Energy Engineering Centre, Energy and Power, Cranfield University, Bedfordshire, MK43 OAL, UK.

\section{ABSTRACT}

Gas-liquid flows in annulus channels are frequently encountered in the underbalanced drilling operation when the gasified drilling fluid is used. Accurate characterization of two-phase flow regimes in such conduits is critically important in order to gain a better understanding of the flow behaviours in the channels, thus to ensure a successful drilling operation achieved. In this paper experimental studies regarding gas-liquid flows in a concentric and fully eccentric horizontal annulus were reported. The test section setups of the flow loop have a length of $10.8 \mathrm{~m}$, with outer and inner pipe diameters of $0.0768 \mathrm{~m}$ and $0.060 \mathrm{~m}$ respectively. Air and water at atmospheric pressure constituted the gas and liquid phases and the range of gas and liquid superficial velocities investigated during this study was $0.14-24 \mathrm{~m} / \mathrm{s}$ and $0.15-2.78 \mathrm{~m} / \mathrm{s}$ respectively. Flow regimes observed in both annulus setups by high speed camera imaging were dispersed bubble, elongated bubble, slug, wavy slug, churn, wavy annular and annular. A detailed description of the flow regimes with different features are presented together with high quality images. The local liquid holdup time series together with its probability density function (PDF) are used to gain more insights about the characteristics of the observed flow regimes. Effects of the annulus eccentricity on the observed flow regimes are also investigated. It is found that the annulus eccentricity affects the shape and structure of the elongated bubble, wavy annular and annular flow regimes. It is also observed that the annulus eccentricity causes the transition from elongated bubble to dispersed bubble to take place at higher liquid superficial velocities. It is also found that in the fully eccentric annulus causes transitions between different flow regimes to occur at higher liquid and lower gas superficial velocities when compared with that of concentric ones. An improved flow regime map is proposed based on gas and liquid Froude numbers by integrating the test results from this study with over 1000 data points found in literature.

Keywords: Concentric, Fully eccentric, Two-phase flow, Annulus, Horizontal, Experimental

\section{$1 \quad 1$ Introduction}

Lage et al.,(2000) undertook small scale experimental and theoretical studies of two-phase flow in horizontal and slightly deviated fully eccentric annuli. The annulus setup was $50 \mathrm{~m}$ long, having outer (Do) and inner (Di) diameters of 0.1016 and 0.0508 $\mathrm{m}$ respectively. Test fluids utilized were air-water and dieselnitrogen mixtures. Flow regimes identified include dispersed bubble, stratified, intermittent and annular flows. However, their data points were too few and could not produce a complete view of flow regime maps.

For their part, Ekberg et al.,(1999) studied flow regimes in narrow horizontal annuli. Experiments were conducted in two different annuli with Do and Di of $0.00863 \& 0.0066 \mathrm{~m}$ for the first annulus and $0.0352 \& 0.03315 \mathrm{~m}$ for annulus two. Flow regimes observed were classified by the researchers as plug, slug, dispersed bubble, churn as well as other hybrid regimes. The annulus setups were small and not likely to be encountered in the oil and gas industry.

Zhou et al., (2004) performed extensive air-water experiments in a large scale annulus with Do of $0.2124 \mathrm{~m}$ and Di of $0.089 \mathrm{~m}$. Observed flow regimes included stratified smooth, stratified wavy, slug, stratified to slug, slug to dispersed bubble and slug to annular. They also developed theoretical basis for flow regime transitions.

Omurlu, Metin and co-workers (Omurlu et al., 2006; Metin \& Ozbayoglu, 2007) studied extensively two-phase flow through fully eccentric horizontal annulus. Their experimental setups consisted of different Do $(0.0932,0.1143 \mathrm{~m})$ and Di (0.0488 and $0.05715 \mathrm{~m}$ ). Flow regime identification was by visual means and limitations in their setup meant that mainly the intermittent flow regime was observed during their study. They proposed a mechanistic model based on representative diameter for flow regime determination in fully eccentric annulus.

Mendes et al., (2011) studied flow regimes in inclined gasliquid flow in annular ducts. The annulus geometry made from borosilicate gas had a length of $10.5 \mathrm{~m}$ and Do $0.111 \mathrm{~m}$ and Di $0.075 \mathrm{~m}$. Air-water flow regimes observed stratified smooth, stratified wavy, plug, slug, churn, bubble and dispersed bubble.

Later on, Osgouei and others (Osgouei \& Ozbayoglu, 2010; Osgouei et al., 2012; 2013) presented studies on two-phase flow in a horizontal annulus having an eccentricity of 0.623 . They presented flow regime determination techniques based on diagquadratic discriminant analysis and suggested in a separate paper flow regime identification based on Artificial Neural Networks.

Gschnaidtner, (2013) undertook experimental studies in a concentric annulus with Do of $0.0515 \mathrm{~m}$ and Di of 0.0333 . Air and water were the test fluids and flow regime identification was 
achieved using video camera recordings. Observed flow regimes were limited to intermittent and bubble flow due to the small range of liquid and gas superficial velocities investigated.

Recently, Nossen et al.,(2017) conducted an experimental study of two-phase flow in horizontal and inclined annuli. The annulus test section was concentric, having outer and inner diameters as 0.1016 and $0.0508 \mathrm{~m}$ respectively. Test fluids used were SF6 gas - water and SF6 gas - Exxsol D60 oil. Flow regimes observed during their studies were Slugs, large waves, very low frequency slugs and transitional as a very limited range of gas and liquid superficial velocities were investigated.

In summary, a review of related literature points to the fact that the flow structure in the annulus setup is different from those observed in circular pipes due to flow obstruction by the central pipe. As a result, the characteristics of the flow regimes are different. There is a lack of detailed information on the flow regimes encountered in horizontal annuli, as most studies undertaken to characterize flow regimes were based on visual observation, which proved challenging due to the obstruction and deformation in vision caused by the unique geometries of the flow channel. Also, in spite of the fact that in some applications e.g. underbalanced drilling operations, annulus eccentricity is an issue for horizontal two-phase flow regimes and their transitions. However, based on available literature, not much attention has been paid to this although most issues relating to vertical annuli have mainly been resolved.

To address these issues, this study presents detailed systematic experimental studies which have been conducted in fairly large (a) horizontal concentric and (b) fully eccentric annuli to characterize flow regimes and their transitions. High speed camera images and ring-type conductance probes designed for this study have been utilized to examine the flow regime features in horizontal annuli.

\section{Experiments}

\subsection{Experimental Setup}

The experimental study have been carried out in the Process Systems Engineering laboratory of the Cranfield University. A simplified schematic diagram of the flow loop is as shown in Fig. 1(a). Air and water were the testing fluids with the air supplied to the flow loop using a screw compressor by AtlasCopco® model GA55 with a maximum discharge pressure of 7.5barg and free air maximum delivery capacity of $638 \mathrm{~m}^{3} / \mathrm{hr}$. Two automated valves (namely VC301 \& VC302) are used in regulating the air flow rate while measurement is undertaken by one of two Rosemount Mass Probar flow meters (FT302 and FT305) with accuracy of $\pm 1.4 \%$. Air flow rates ranging between $0-150 \mathrm{Sm}^{3} / \mathrm{hr}$ are measured by FT302 while flow rates above $150 \mathrm{Sm}^{3} / \mathrm{hr}$ are measured by FT305. Water flow to the flow loop is provided from a water tank with a capacity of $2 \mathrm{~m}^{3}$ using a progressive cavity pump with maximum discharge pressure of 6 barg. The water flow is measured using an Endress \& Hauser Promag 50 electromagnetic flow meter ranging between $0-18 \mathrm{~m}^{3} / \mathrm{hr}$, having an accuracy of $\pm 0.5 \%$. A $2 \mathrm{~m}$ long stainless steel section preceding the annulus test section is allowed for mixing of both phases before it enters the annulus test section where a development length of $1 \mathrm{~m}$ is allowed before the first instrument is placed, and then flows through the entire annulus section.. The fluid mixture exit the annulus test section into a section of circular pipe before emptying into the water tank which is open to the atmosphere, where gas-liquid separation takes place.

The annulus test section is formed using two Polyvinyl Chloride (PVC) pipes with outer pipe diameter (Do) is $0.0768 \mathrm{~m}$ and inner pipe diameter (Di) is $0.060 \mathrm{~m}$ creating a hydraulic diameter of $0.0168 \mathrm{~m}$. it is $10.8 \mathrm{~m}$ in length and the flow observation and measurement sections are placed $6.01 \mathrm{~m}$ away from the point where the fluid mixture enters the annulus which gives a length of 357 pipe diameters. Two GE Druck static pressure transducers model PMP 1400, and a WIKA model A-10 static pressure transducer ranging between $0-6$ barg and accuracy of $\pm 0.25 \%$ of full scale are used to obtain the static pressure in the test section. The fluid mixture temperature is measured by a J-type thermocouple with accuracy of $\pm 2.5^{\circ} \mathrm{C}$. The eccentricity of the annulus is adjusted using $4 \mathrm{~mm}$ stainless steel pins fed through an eccentricity adjuster fabricated from PVC rods by moving the pins in or out depending on the eccentricity desired as depicted in Fig. 1(b). The pins are small enough to ensure that they don't interfere with the two-phase flow that goes through them. Liquid holdup measurement is done using two pairs of conductance probes designed for this study and this $430 \mathrm{~mm}$ long section made from perspex glass also serves as the imaging window.

The two pairs of ring-type conductance probes used for measuring the area-averaged liquid holdup were designed based on the recommendation of Fossa (1998) and flush mounted on the outer pipe of the annulus test section. The probes are designed such that the ratio of the electrode spacing De to the pipe diameter $\mathrm{D}$ is 0.34 resulting in electrode spacing of $26 \mathrm{~mm}$. Two pairs of electrode were used each having a width of $6 \mathrm{~mm}$ and distance of $270 \mathrm{~mm}$ between each electrode pair. A desktop computer using a LabView ${ }^{\circledR}$ based system consisting of National Instruments (NI) connector board interface and connected to the instrumentation using coaxial cables is used for data acquisition. Flow regime images are captured using an OLYMPUS model i-

SPEED 3 high speed camera at 1000 frames per second and adequate lighting is provided using Arrilite 800-W lights.

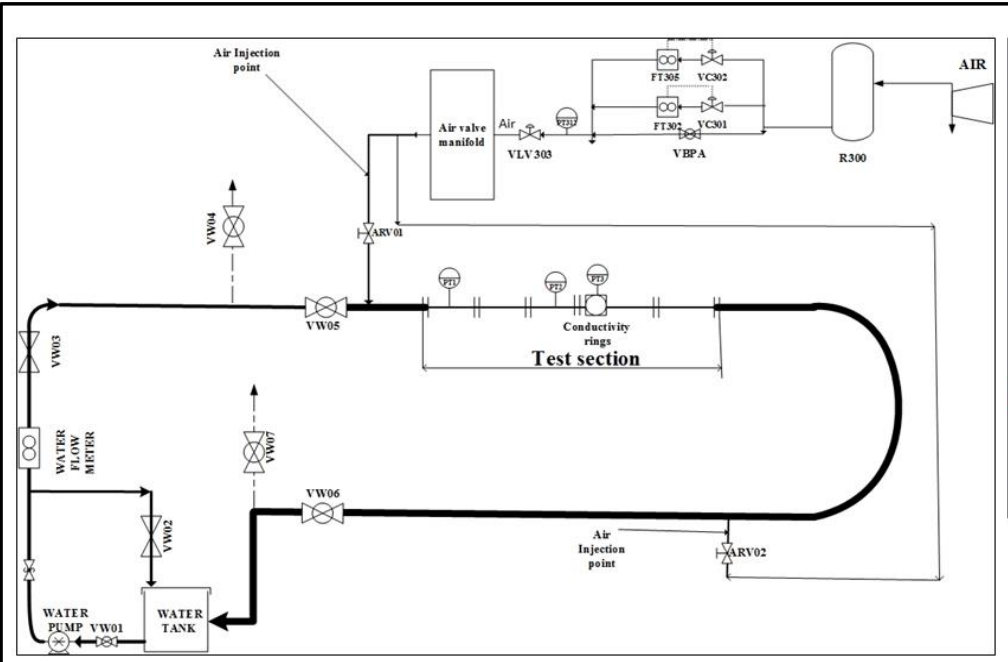

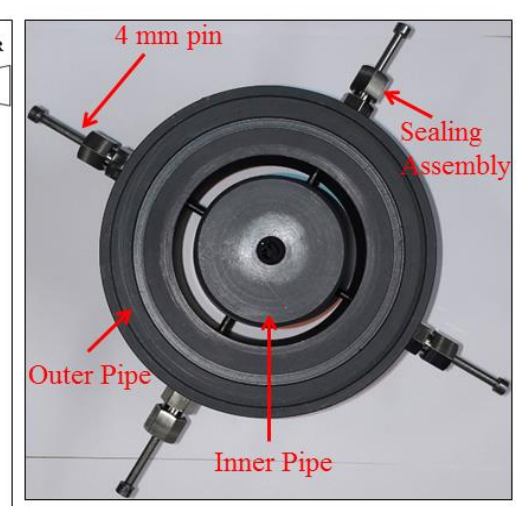

(b) 


\section{$193 \quad 2.2$ Experimental Procedure}

\section{2.2.1 Conductance Probes}

195 The conductance probes employed for this study operate based 196 on the principle that the two-phases employed as testing fluids 197 have different electrical conductivities. Therefore the electrical 198 impedance between two electrodes immersed in a multiphase 199 fluid mixture is determined by the conductance and permittivity 200 of these individual phases, the fraction of the phases, the flow 201 regime observed and the configuration of the sensor. Calibration 202 of the ring-type conductance probes was carried out offline based 203 on the recommendations of Fan \& Yan (2014) for stratified flow 204 in concentric and fully eccentric annulus setups. Known volumes 205 of liquid (water) were introduced into each annulus setup and the 206 corresponding voltages were recorded. A high-level voltage 207 output of $5 \mathrm{~V}$ was obtained when the annulus section was 208 completely filled with water and a low-level voltage output of 0 209 V was observed when the annulus was empty (filled with air). 210 The voltage output from each pair of conductance probe was 211 normalized using maximum voltage value when the annulus was 212 filled with water for each annulus setup, this produced a 213 dimensionless value. A non-linear relationship was obtained 214 between the liquid holdup and the voltages for each annulus setup 215 and during experimental runs, the obtained voltages are plugged determined as such. The uncertainty of the conductance probe measurements are found to be within $\pm 2 \%$ of indirect measurements.

\subsubsection{Experimental Scheme}

The annulus section eccentricity is adjusted as appropriate using the $4 \mathrm{~mm}$ stainless steel pins earlier described. During this study, two eccentric positions were investigated; (i) concentric and (ii) fully eccentric annulus setups.as depicted in Fig. 2 Before any experimental program is commenced, offset values for the

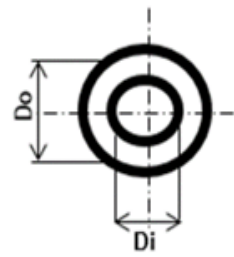

(a)
226 flow meters and pressure transducers are determined from an 227 empty test rig. The liquid flow rate is established using the pump 228 control system which consists of manual valves, a variable speed 229 controller and the water flow meter. The air flow rate at given 230 values (in $\mathrm{Sm}^{3} / \mathrm{hr}$ ) is injected into the flow loop by using the 231 Emerson DeltaV PID controller implemented in the air supply 232 section. A five minute period is allowed for flow stabilization 233 before data is logged for 180 seconds for each flow condition at a 234 sampling frequency of $100 \mathrm{~Hz}$. The high speed camera records 235 videos at $1000 \mathrm{fps}$ for a total of $60 \mathrm{~s}$. The range of gas and liquid 236 superficial velocities investigated were $0.16-24 \mathrm{~m} / \mathrm{s}$ and $0.15-$ $2372.78 \mathrm{~m} / \mathrm{s}$ respectively. During each test run, the air standard 238 volumetric flowrate is kept constant while the liquid flowrate is 239 increased at intervals of $0.0005 \mathrm{~m}^{3} / \mathrm{s}$. This is repeated until the 240 entire range of flowrates is covered. Visual observation and 241 analysis of high speed camera recordings as well as statistical 242 evaluation of area averaged liquid holdup values obtained using 243 conductance probes for each test condition is undertaken and the 244 flow regimes are identified.

\section{Results \& Discussion}

\section{3.1 Visual Characterization of Flow Regimes}

Characterization of flow regimes is achieved using images 248 obtained from high speed camera. This involved playing back the 249 recording of flow for each test condition in slow motion, which 250 enabled the visualization of the phase distribution in the annulus 251 setup under study. Similar flow regimes were identified in both 252 annulus setups with subtle differences in some cases. The flow 253 regimes identified include dispersed bubble, elongated bubble, 254 slug, wavy slug (classified for this study), churn, wavy annular 255 and annular flow regimes. Limitations in the experimental setup 256 means the stratified flow regime was not encountered.

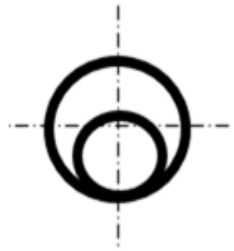

(b)

Figure 2: Schematic of (a) Concentric annulus (b) Eccentric annulus.

Where $P_{G}$ and $T_{G}$ are the initial pressure and temperature of the gas phase $\left(101325 \mathrm{~Pa}\right.$ and $\left.15^{\circ} \mathrm{C}\right)$ respectively, $Q_{G}$ is the volumetric flowrate in $\left(\mathrm{Sm}^{3} / \mathrm{s}\right), T_{M}$ and $P_{M}$ are the temperature and pressure of the two-phase mixture measured at the test section and $A$ is the cross sectional area of the annulus.
Typical photographic representations of the flow regimes obtained are presented in Figure 3 and a brief description of each regime is presented below:

3.1.1 Dispersed Bubble Flow: The dispersed bubble flow regime is observed at high liquid and low gas superficial velocities. Tiny gas bubbles are dispersed in a continuous liquid phase concentrated initial close to the top of the annulus cross section. The mechanism for the formation of this flow regime is the breakdown of gas plugs during the elongated bubble or slug flow regimes. Increasing the liquid superficial velocity results in a more even distribution of gas bubbles in the annulus section.

3.1.2 Elongated Bubble Flow: Also known as the limiting case of slug flow. It is encountered at very low gas and liquid superficial velocities. Characterized by alternating liquid body which fills the entire annulus cross section and gas plugs trapped at the top of the annulus. The shape of the gas plug observed 
286 depends on the annulus eccentricity under study. No gas bubbles 287 are entrained in the liquid body.

288 3.1.3 Slug Flow: This flow regime is similar to elongated bubble 289 but occurs at higher gas superficial velocities. Initially preceded 290 by a stratified smooth or wavy interface depending on the 291 superficial gas velocity. The stratified system is followed by 292 faster and shorter moving liquid body with higher energy 293 intensity than those observed in elongated bubble flow. The 294 liquid body wraps itself around the inner pipe of the annulus and 295 contains some entrained gas bubbles flowing close to the top or 296 centre of the annulus, due to a decrease in flow liquid holdup and 297 increased turbulence.

298 3.1.4 Wavy Slug Flow: This flow regime was classified as such 299 for this study and is similar to what was observed by Nossen et 300 al.,(Nossen et al., 2017) and classified as large wave flow. It is 301 characterized by a long liquid film region during wave 302 development, followed by a small liquid body which briefly 303 bridges the top of the annulus, after which it seems to lose energy 304 and is pushed away by a following wave. Some gas bubbles are 305 entrained in the small liquid body at higher liquid superficial 306 velocities. It has some of the features of slug flow but possesses 307 its own unique feature to be classified as a flow regime.

308 3.1.5 Churn Flow: The churn flow regime is similar to the slug 309 flow regime but is characterized by a chaotic liquid phase 310 containing a large amount of entrained bubbles travelling with an
311 oscillatory motion. No clear boundaries can be observed for both 312 phases. The mechanism of this regime is an increase in the gas 313 void fraction resulting in the breakdown of the continuous nature 314 of the liquid body that follows each successive Taylor bubble.

315 This causes a collapse of the slug which falls back and is mingled

316 with the one following. It has been confirmed in the past from

317 experimental studies that the churn flow regime could not exist in

318 horizontal or shallow inclined two-phase flow. In vertical

319 upwards flows people use "churn flow" to describe an

320 intermediate region between slug and annular flows in the flow

321 regime map (Hewitt and Jayanti, 1993). Similar to this, churn

322 flow observed in the annulus also sits between the slug and

323 annular flow regimes.

324 3.1.6 Wavy Annular Flow: Occurring at low liquid and high gas 325 superficial velocities, this flow regime is characterized by a 326 continuous gas core with some entrained liquid in the annulus 327 centre, a thin liquid film at the top of the annulus and a thicker 328 film at the bottom with a wavy interface. The annulus 329 eccentricity affects the observed film level and interface.

330 3.1.7 Annular Flow: At higher gas superficial velocities than for 331 wavy annular flow the annular flow regime is encountered. A 332 smooth liquid film is observed at the top and bottom of the 333 annulus. The film at the bottom is thinner when compared with 334 those of the wavy annular flow. 


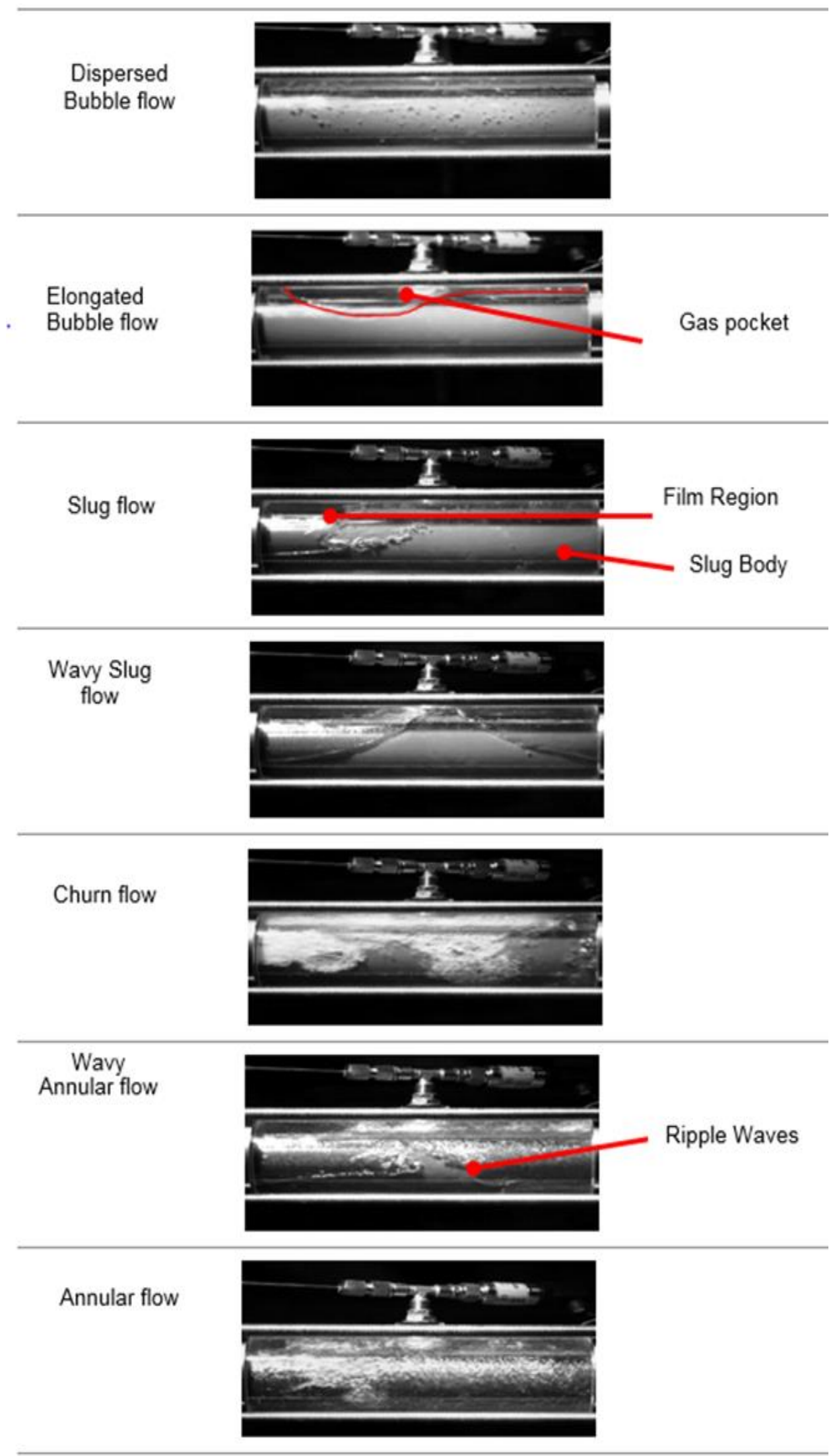

339 3.2 Flow Regime Characterization using Local Liquid Holdup 340 Measurements

341 Further characterization of the flow regimes in horizontal 342 annuli is undertaken using a combination of time series and 343 Probability Density Function (PDF) plots of liquid holdup 344 obtained from conductance probes. Conductance probe 345 techniques have been employed in the past by researchers 346 including Barnea et al.(1980), Kelessidis \& Dukler (1989) and 347 Das et al.(1999) for flow regime classification. The raw voltage
348 values obtained from conductance probes are converted to 349 instantaneous liquid holdup by using obtained calibration curves 350 for each annulus setup studied and plotted on a time series plot.

351 Further statistical analysis of the liquid holdup plots were

352 conducted to clearly identify each flow regime observed during

353 gas-liquid flow in horizontal annuli and compared with visually

354 observed flow regimes. Representative time varying liquid

355 holdup and PDF plots are presented in Fig. 4 for horizontal

356 concentric annulus. 

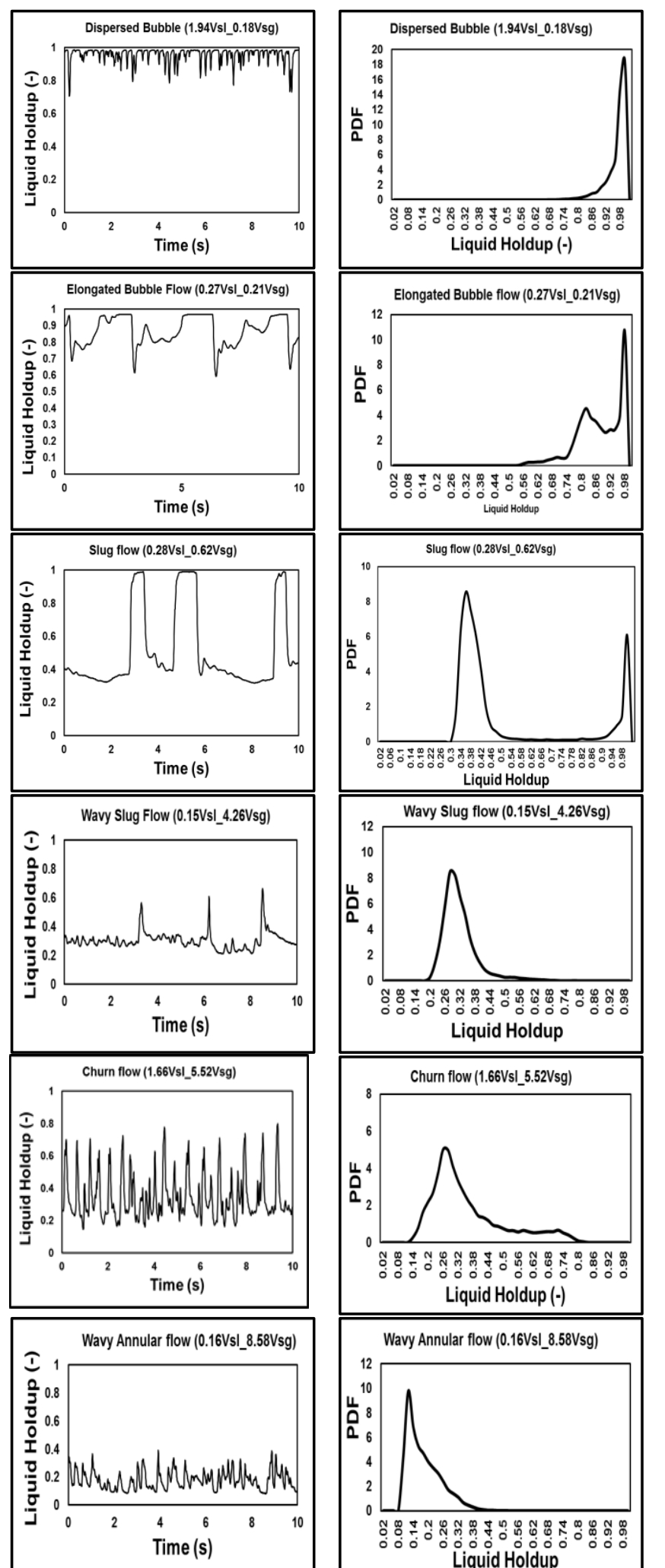

Wavy Annular flow (0.16Vs__8.58Vsg)
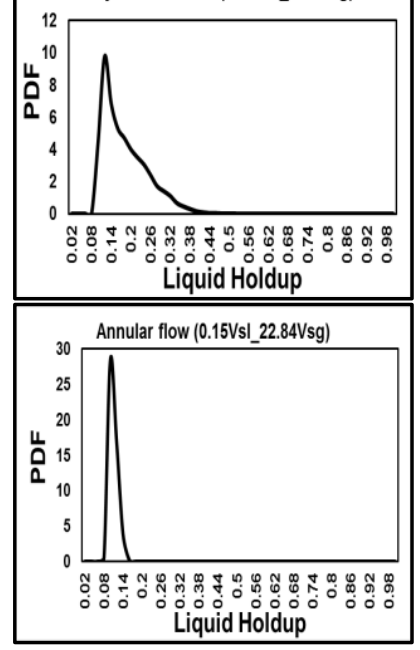

Figure 4: Representative time series and PDF trends for flow regimes in horizontal concentric annulus

For the dispersed bubble flow regime, a steady uniform oscillation of the time varying liquid holdup around a value of 1 , gives an indication of the presence of spherical bubbles dispersed
363 in a continuous liquid phase. The PDF plot is unimodal having its 364 peak value at holdup value 0.97 .

365 During the elongated bubble flow regime, the time varying 366 liquid holdup plot is observed to fluctuate intermittently from a 367 crest value of 0.7 to a crest value of 1 . The higher crest value 368 corresponds to full liquid filling the annulus section between the 369 ring electrodes while the lower crest value indicates the passage 370 of the elongated gas bubble through parts of the probe. The PDF 371 feature of this flow regime indicates two peaks close to each 372 other at high liquid holdup values.

373 Pulsating probe traces are observed for the slug flow regime, 374 which indicates how the slug liquid body and Taylor bubbles
375

376

377

378 alternate in the annulus section between the ring electrodes. A bimodal PDF trend is observed with two very distinct peaks. One peak exists within liquid holdup range between $0.30-0.50$, while the second peak exists between ranges of $0.7-1.0$.

The nature of the wavy slug is seen by the width and amplitude of the time varying liquid holdup plot at low holdup values. Small waves are represented by the zig zag spikes at low holdup values, while a peak value at higher holdup values signifies a small liquid body that just touches the annulus top. The PDF trend for this regime is unimodal in nature with its peak at low liquid holdup values, with the second peak observed in slug flow at higher liquid holdup values disappearing.

Churn flow is characterized by its rowdy nature and this is evident in the time varying liquid holdup plots, where random peaks and troughs are observed. The observed PDF trend is unimodal with peak at low holdup values similar to what was observed in wavy slug flow. However, the area under the curve is large cutting across a wide liquid holdup range. Also low but non-zero PDF values are observed at liquid holdup values up to 0.8 .

Wavy annular flow shows a probe trend which reflects the effect of unstable aerated waves passing through it, with most of the liquid flowing at the bottom of the annulus as a film. A unimodal PDF plot located at low holdup values with peak value averagely around 0.25 . It is distinguishable from the annular flow regime by its larger area under the curve and low PDF value.

Finally, small spikes are observed consistently about low holdup values during the annular flow regime when time varying instantaneous liquid holdup values are plotted. These spikes indicate a wavy interface and the film thickness is proportional to the mean liquid holdup value. A single PDF peak is obtained at low holdup values near 0 . It has a smaller area under the curve when compared with the wavy annular flow regime but a higher PDF value.

These classifications are used in conjunction with high speed camera images to classify flow regimes accurately in horizontal annuli.

\subsection{Effect of Annulus Eccentricity on Flow Regimes}

As stated earlier, two different annulus setups were used for the experimental investigations presented in this study; (a) the concentric annulus and (b) the fully eccentric annulus. The fully eccentric annulus has the inner pipe in the configuration lying at the bottom of the outer pipe forming a geometry shaped like a half moon which is different from the concentric annulus geometry. A scenario where the annulus eccentricity may be changing can be encountered during underbalanced drilling with drill pipe (inner pipe) rotation as the well is being drilled. The annulus inner structure affects the distribution of phases and as such may influence some of the flow regimes observed.

At the low gas and lowest liquid superficial velocities $(0.21$ $\mathrm{m} / \mathrm{s}$ and $0.15 \mathrm{~m} / \mathrm{s}$ respectively) investigated during this study, the elongated bubble flow is observed in the concentric annulus while the slug flow regime is observed in the fully eccentric annulus. A larger flow area is available at the top of the annulus for the gas phase to occupy in the fully eccentric annulus when compared with a small annulus gap in the concentric annulus. Therefore at this low gas flow rate, the gas phase in the eccentric annulus has sufficient contact area and energy to sweep the liquid phase to bridge the annulus wall intermittently forming slug flow while the gas phase is trapped as an elongated gas bubble in the small concentric annulus gas at the top of the annulus because of 
small gas flow area and low energy. Fig 5(a) and (b) show the high speed image and PDF trends for this flow condition in

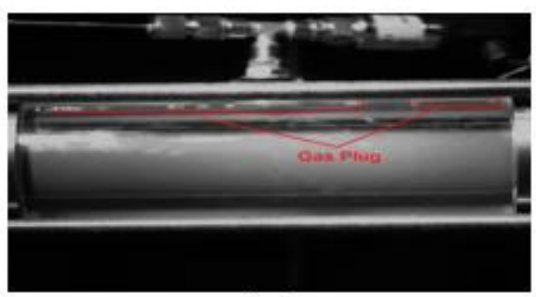

(a)

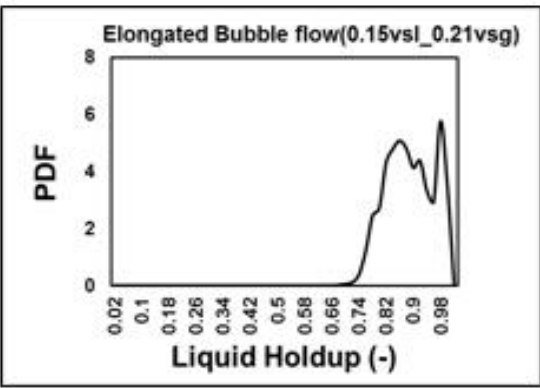

(b)
438 horizontal concentric annulus respectively while (c) and (d) show

439 those for the fully eccentric annulus.

Figure 5: Effect of annulus eccentricity on flow regimes (Vsl=0.15 m/s; Vsg $=0.21 \mathrm{~m} / \mathrm{s}$ ) (a) Elongated bubble flow in concentric annulus (b) Elongated bubble flow PDF trend in concentric annulus (c) Slug flow in fully eccentric annulus (d) PDF trend for Slug flow in fully eccentric annulus.

The bubble shape observed in the elongated flow regime is also affected by the annulus eccentricity. Fig. 6(a) shows the bubble shape observed in the concentric annulus. It is shaped as a flatworm and is shorter in length when compared with the bubble shape in Fig 6(c) which is the bubble shape in fully eccentric annulus. The PDF trends for both annulus are shown in Fig. 6(b) and (d) for concentric and fully eccentric annulus respectively. The effect of the bubble shape is captured in this trend where for the concentric annulus, the tiny bubble shape and length is

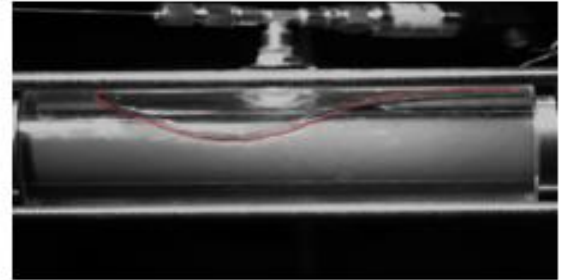

(a)

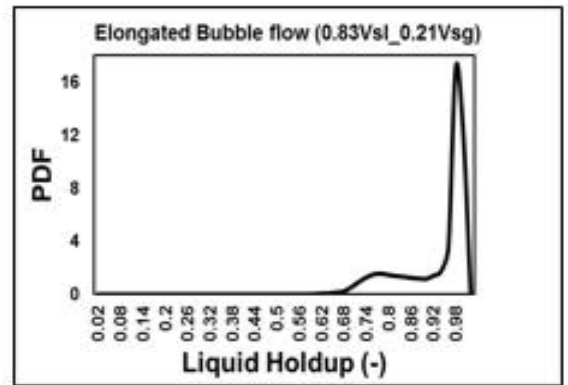

(b)
453 reflected in the observed peaks at high liquid holdup values. On 454 the other hand, the PDF trend for the elongated bubble flow 455 regime in fully eccentric annulus captures the large bubble length 456 and size which is reflected in the observed peaks high and lower 457 liquid holdup values. Also, the highest peak in the concentric 458 annulus has a higher PDF value when compared with that of the 459 fully eccentric annulus. Generally, the slug flow region is largely 460 unaffected by the annulus eccentricity and is the dominant flow 461 regime in both annulus setups.

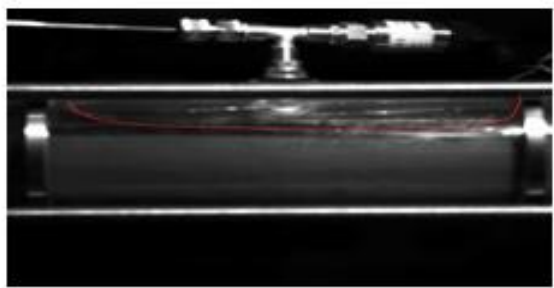

(c)

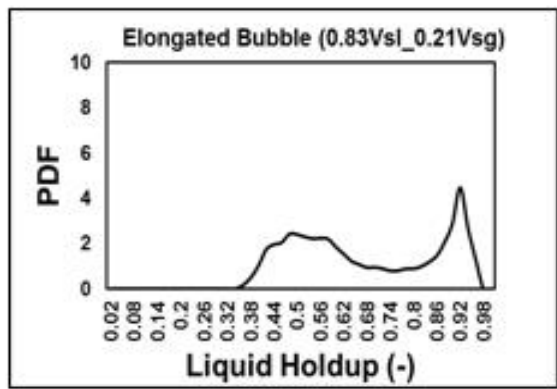

(d)

Figure 6: Typical elongated bubble flow (Vsl $=0.83 \mathrm{~m} / \mathrm{s} ; \mathrm{Vsg}=0.21 \mathrm{~m} / \mathrm{s}$ ) (a) concentric annulus (b) PDF trend for concentric annulus (c) fully eccentric annulus (d) PDF trend for fully eccentric annulus

The liquid film height observed in the wavy annular and annular flow regimes are also affected by annulus eccentricity. In Fig 7, typical annular flow regime images are presented for both the concentric annulus and the fully eccentric annulus. Fig 7(a) shows representative liquid film height in the concentric annulus during annular flow while Fig. 7(c) shows that for a fully eccentric annulus. A higher liquid film height is observed in the fully eccentric annulus when compared with the concentric annulus. This is because of the impact of the flow geometry in
474 the fully eccentric annulus. The inner pipe restricts the flow of 475 the liquid phase at the bottom of the annulus resulting in a higher 476 liquid film. This is captured by the PDF trends presented in Fig 477 7(b) and (d) for concentric and fully eccentric annulus 478 respectively. A similar scenario is observed for the wavy annular 479 flow regime. It is envisaged that the variation of the flow channel 480 geometry due to eccentricity would affect phase separation of the 481 flow, i.e. the larger the eccentricity, the easier the gas/liquid 


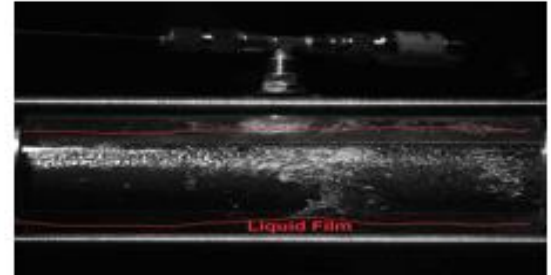

(a)

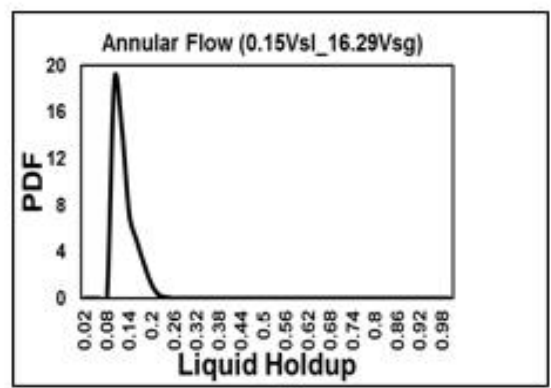

(b)

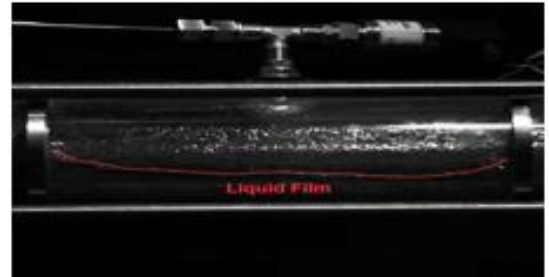

(c)

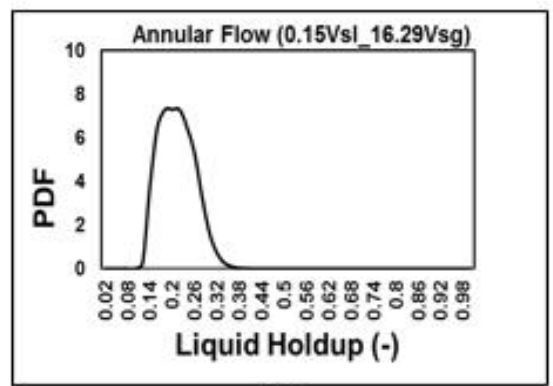

(d)

Figure 7: Typical annular flow regime (Vsl $=0.15 \mathrm{~m} / \mathrm{s} ; \mathrm{Vsg}=16.29 \mathrm{~m} / \mathrm{s})$ in (a) concentric annulus, (b) PDF trend for concentric annulus (c) fully eccentric annulus (d) PDF trend for fully eccentric annulus

\subsection{Flow Regime Maps}

\subsubsection{Experimental Flow Regime Maps}

Flow regime maps were developed from experimentally observed flow regimes for both annulus setup investigated for this study. The coordinates were the superficial liquid and gas velocities as ordinate and abscissa respectively. The effect of annulus eccentricity on observed flow regime transitions was also studied. As depicted in Fig. 8(a), at the lowest liquid and gas superficial velocities investigated in the concentric annulus, the elongated bubble flow is first encountered, Fig. 8(b) on the other hand shows at in the fully eccentric annulus at the same conditions, the slug flow regime is encountered. The slug flow regime is the predominant flow regime in both annulus setup. Similarly, the effect of annulus eccentricity on experimental flow regime transition are presented in Fig.9. The flow regime transitions were drawn arbitrarily and comparisons were made by superimposing both flow regime transitions on one map. It can be

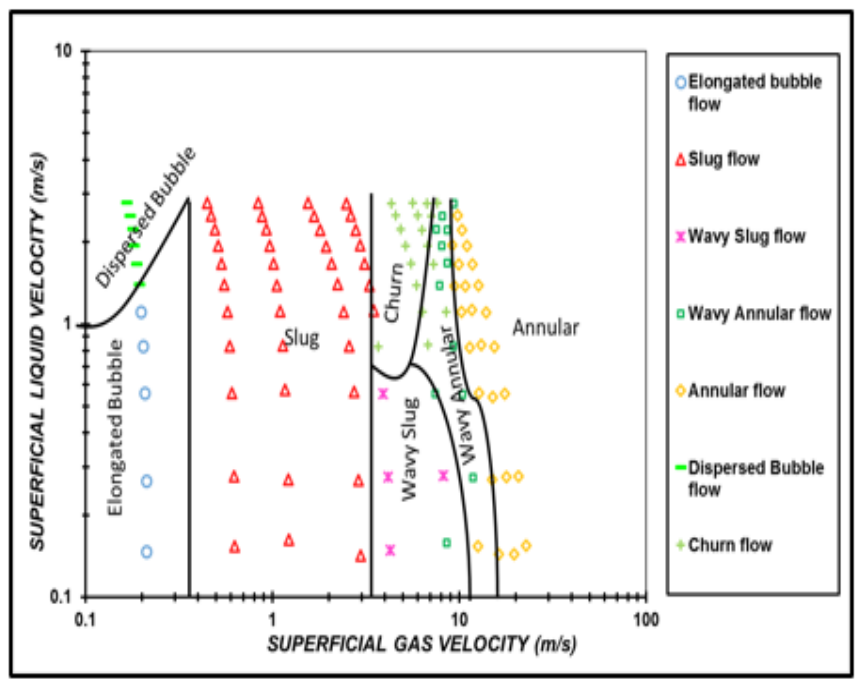

(a)
505 observed in Fig. 9 that the transition to elongated bubble and 506 dispersed bubble flows in the fully eccentric annulus, take place 507 at Vsl of $0.22 \mathrm{~m} / \mathrm{s}$ and $1.56 \mathrm{~m} / \mathrm{s}$ respectively, which is higher than 508 that at which the transition takes place in the concentric annulus $509(\mathrm{Vsl}=0.10 \mathrm{~m} / \mathrm{s}$ and $0.99 \mathrm{~m} / \mathrm{s}$ respectively). This is due to the 510 geometry effect and the distribution of the phases in both annulus 511 setups. More area for gas phase to occupy in the fully eccentric 512 annulus means that the elongated bubble flow regime will occur 513 at higher liquid superficial velocities. For this same reason, 514 higher liquid flow rates are required to breakdown to large gas 515 plugs in this setup when compared with the concentric one.

516 Generally speaking, the transitions from elongated bubble to slug,

517 slug to wavy slug and wavy slug to annular flow regimes occur at

518 lower gas superficial velocities in the fully eccentric annulus

519 when compared with the concentric one. This shift appears to be 520 consistent with the observed effect of eccentricity on phase 521 separation. 


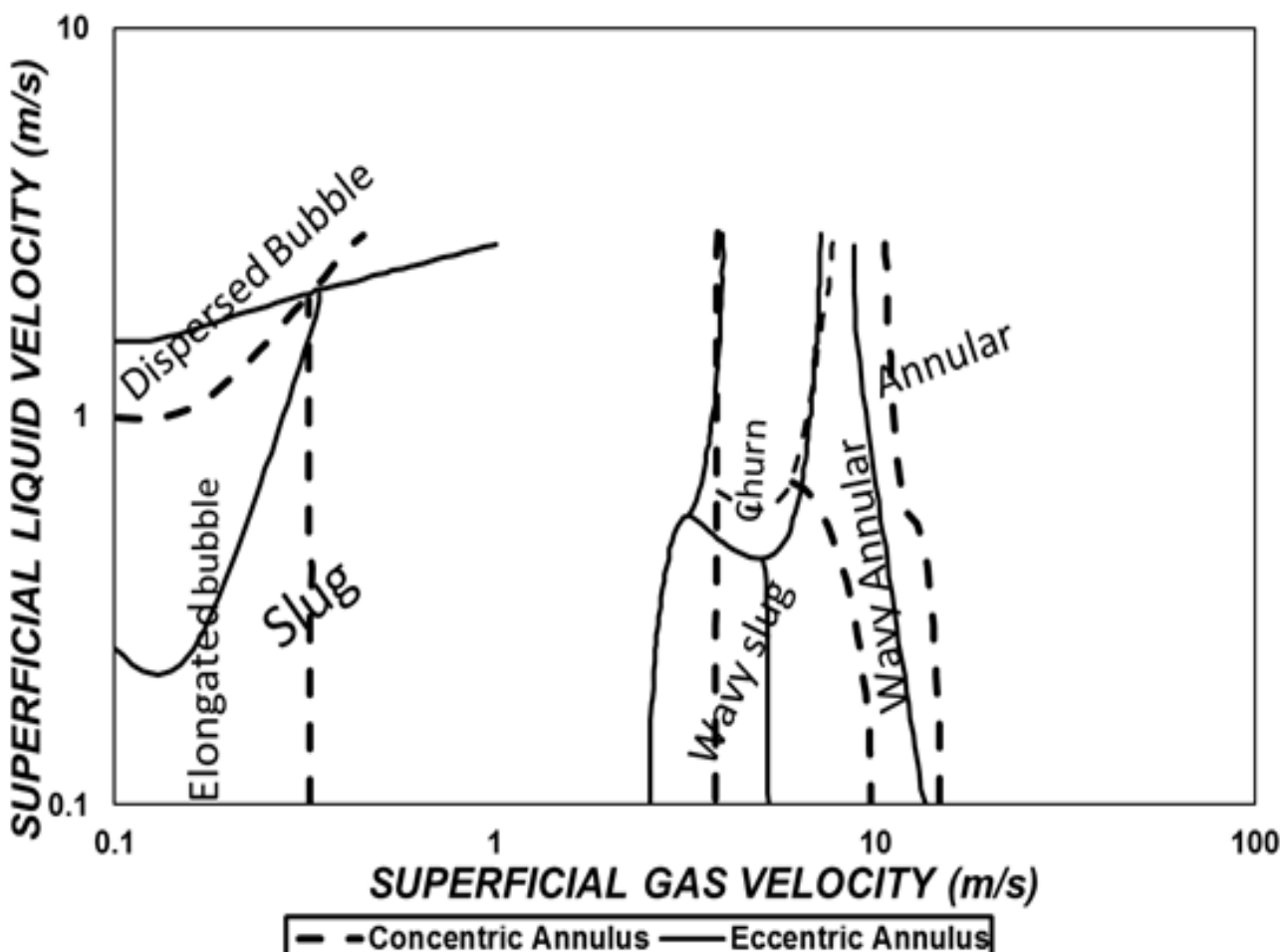

\section{3.4.2 Effect of Regime Transitions on PDF Features}

\section{The effect of gas and liquid superficial velocities on the flow} regimes was also studied using PDF features as presented on Fig.10. The flow regimes are observed to transition with increasing gas and liquid superficial velocities from elongated bubble at the lowest gas superficial velocity to annular flow at the highest gas superficial velocity and this is reflected on the PDF plots. Also, the shape and structure of the PDF trends are affected due to increase in flowrates.

For example, the influence of gas superficial velocity increase can be observed at liquid superficial velocity of $0.27 \mathrm{~m} / \mathrm{s}$. The elongated bubble flow observed at gas superficial velocity of 0.21 $\mathrm{m} / \mathrm{s}$ transitions to slug flow regime at Vsg towards $1.21 \mathrm{~m} / \mathrm{s}$ due to an increase in the area occupied by the gas phase. This is observed in the liquid holdup time series plot where the average liquid holdup value is reduced as well as the length of time the liquid holdup is observed at very high liquid holdup values. Similarly, the PDF trend shows two distinct peaks with the higher peak observed at lower liquid holdup values showing the effect of the gas void fraction increase in the annulus. A further increase in Vsg to a high value $(16.29 \mathrm{~m} / \mathrm{s})$ results in further increase in the gas void fraction which is reflected in the lower averaged liquid holdup values observed in the holdup time trace which has wavy spikes indicating the wavy nature of the flow. The PDF trend shows the disappearance of the peak observed at higher holdup vales, rather a single peak is observed at very low holdup.

The effect of increase in liquid superficial velocities can also be observed in Fig. 10. An increase in Vsl from 0.27 toward 1.94 $\mathrm{m} / \mathrm{s}$ at $\mathrm{Vsg}$ of $0.21 \mathrm{~m} / \mathrm{s}$ results in an increase in the liquid holdup and corresponding reduction on the area occupied by the gas phase in the annulus setup. Large gas plugs are broken down to smaller gas bubbles reflected in the higher frequency of downward spikes noticed on the holdup time traces. The PDFs on the other hand shows with increase in Vsl, the gradual disappearance of the lower value peak observed in the elongated flow regime, leaving just a single peak at holdup value of around 0.95 for the dispersed bubble flow.

At Vsg from 1.21, increasing Vsl from 0.27 towards $1.94 \mathrm{~m} / \mathrm{s}$ gives some understanding of the effect of increased liquid holdup on the slug flow regimes observed in the annulus configuration studied. Increased liquid holdup results in more frequent slug body being observed by the probes as shown by increased peaks
569 and troughs in the holdup time series plots. On the other hand, the 570 PDFs show a more dominant second peak at higher holdup values 571 at higher Vsl values with the peak at lower holdup values 572 gradually diminishing in value.

573 During two-phase flow at Vsg of $16.29 \mathrm{~m} / \mathrm{s}$, increasing Vsl 574 from 0.27 to $1.94 \mathrm{~m} / \mathrm{s}$ showed the effect of increasing liquid 575 flowrates in the annular flow region. The short spikes noticed at 576 the lowest Vsl gradually become more frequent and occur at 577 higher holdup values as observed on the holdup time series plot. 578 This gives an indication of the increased wavy interface of the 579 liquid film at the bottom of the annulus. With regards to the PDF 580 trend, the area under the PDF curve increases with increase in Vsl 581 and shift the single observed peak from near enough zero to 582 higher holdup value up to 0.28 . At Vsl of $1.94 \mathrm{~m} / \mathrm{s}$, the flow 583 transitions to wavy annular flow is due to reduced energy of the 584 gas phase.

585 Due to constraints in space, all the observable flow regime 586 transitions are not presented in this article but it is worth 587 mentioning that at other gas and liquid superficial velocities 588 investigated during this study, transition to wavy slug and churn 589 flow regimes were also encountered and the effect of flowrate 590 increases affected the observed holdup time series and PDF 591 trends for these regimes.

\section{3.4.3 Comparison of Flow Regime Maps}

593 The experimentally developed flow regime map in horizontal 594 concentric annulus is compared with the flow regime map 595 proposed by Osgouei et al.,(2010) for flow through horizontal 596 concentric annulus as presented in Fig. 11. It can be observed the 597 flow regime transitions from literature developed by Osgouei et 598 al., (2010) is unable to predict the slug, churn and annular flow 599 regimes accurately. The wavy annular flow regime is the only 600 regime predicted fairly accurately by the map. 


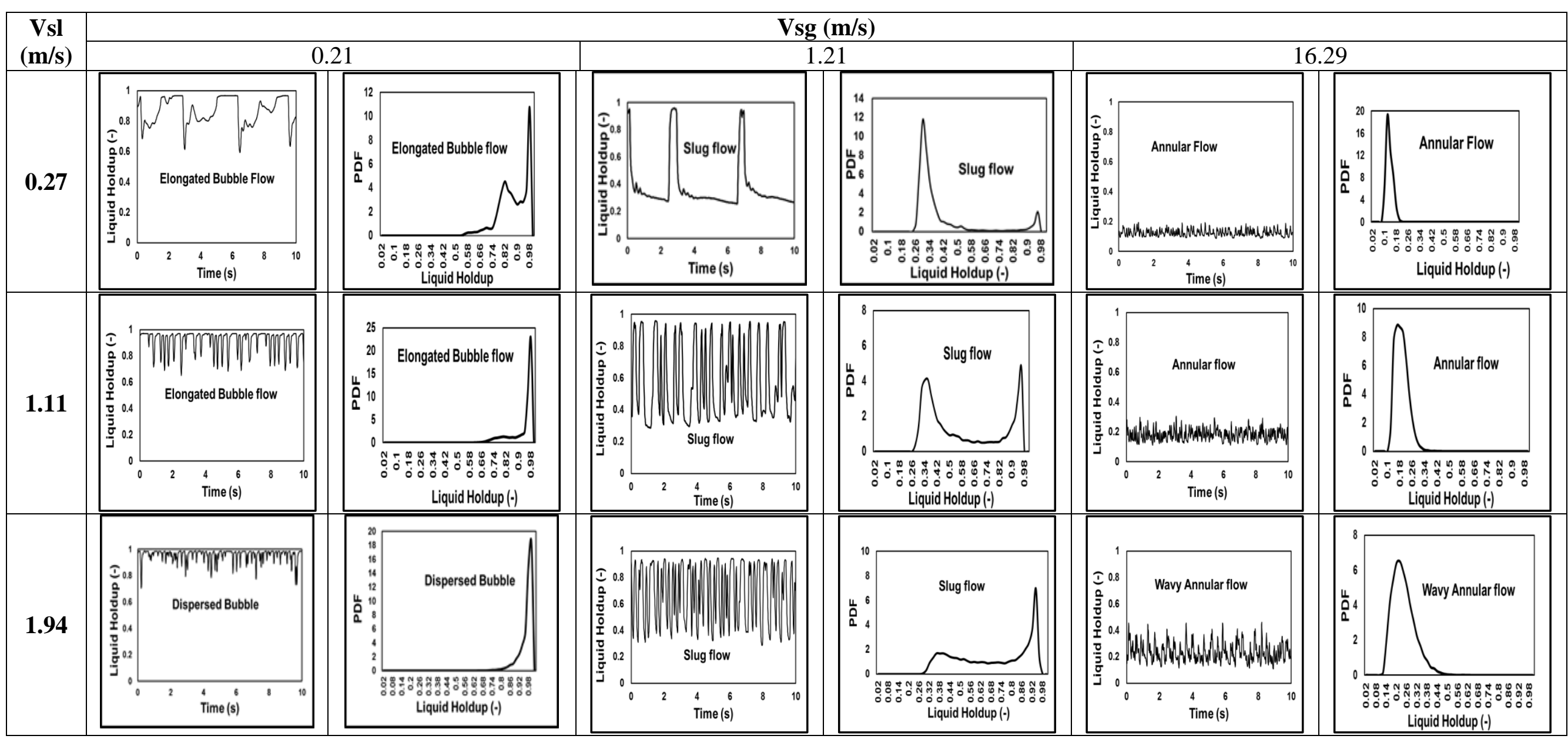

Figure 10: Effect of gas and liquid superficial velocities on Time series and PDF trends in horizontal concentric annulus 


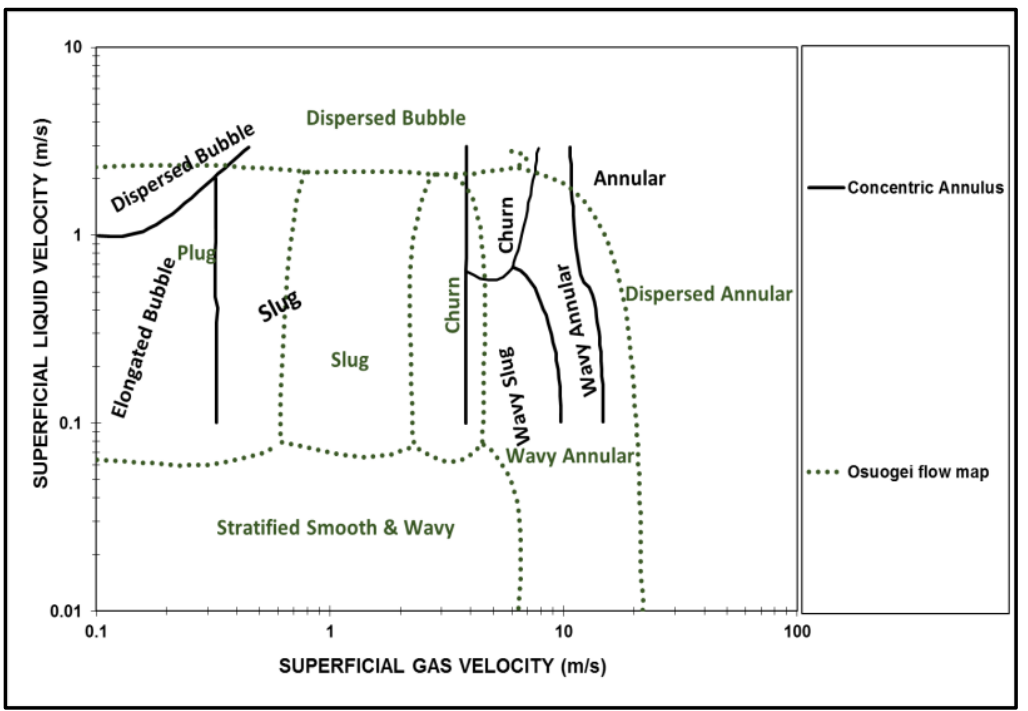

Figure 11: Comparison of flow regime maps in literature with concentric eccentric annulus flow regime map

\subsection{Development of Flow Transition Parameters}

The differences observed in the compared flow regime maps, as well as lack of studies which accurately characterize flow regimes and their transitions in horizontal annulus, shows the need to develop flow regime transition parameters. Exactly 1174 experimental data points integrated from literature and experiments are harnessed to develop this model. Data was obtained from studies by Sunthankar et al.,(2000), Zhou et al.,(2004), Omurlu et al.,(2006), Ozbayoglu \& Omurlu (2007), Osgouei et al.,(2010), Mendes et al.,(2011), Gschnaidtner (2013), Nossen et al.,(2017) and integrated with experimental data from the fully eccentric annulus setup. The developed flow regime transitions in this study is based on different annulus eccentricities, hydraulic diameters, fluid properties as well as gas and liquid superficial velocity ranges. Most of the data is assumed to have been collected under ambient temperature and pressure as operating conditions were not reported in the studies. A flow regime map is proposed based on modified gas and liquid Froude numbers. The Froude number is an important dimensionless parameter for flow regime identification and gives an indication of the ratio of the inertial forces to the external field. The gas and liquid Froude numbers are defined as:

$$
\mathrm{Fr}_{G}=\sqrt{\frac{\rho_{G V_{S G}}}{\left(\rho_{L}-\rho_{G}\right) D_{H} g \cos \theta}}
$$

$$
\operatorname{Fr}_{L}=\sqrt{\frac{\rho_{L V_{S L}}}{\left(\rho_{L}-\rho_{G}\right) D_{H} g \cos \theta}}
$$

Where $V_{S L}, V_{S G}, g, D_{H}$ are the liquid superficial velocity, gas superficial velocity, gravitational acceleration and hydraulic diameter respectively; while $\rho_{L}, \rho_{G}$ are the liquid and gas densities respectively. Similar flow regimes were classified using different names in the studies from where the database utilized for the flow regime transition is gotten; and as such, for this study, certain flow regimes have been grouped under one broad heading for the purpose of developing the transition parameters. Churn, wavy slug, elongated bubble and slug flow regimes are classed under the intermittent flow, dispersed bubble, and bubble flow are classed as bubble flow, while wavy annular and annular flow regimes are grouped under annular flow.

The transition parameters are as follows:

Stratified Flow to Intermittent Flow

$$
F r_{L} \geq-0.078 \ln F r_{G}+0.129 ; \quad F r_{G} \leq 0.025
$$

647 Stratified Flow to Annular Flow

$$
F r_{L} \geq-0.0247 \ln F r_{G}-0.2 ; F r_{G}<0.04
$$

648 Intermittent to Bubble Flow

$$
F r_{L} \geq 4.115 e^{19.4 F r_{G}} \text { and } F r_{G}<0.04
$$

649 Intermittent to Annular Flow

$$
\begin{aligned}
F r_{L} \geq-122.9 F r_{G}{ }^{2}-12.28 F r_{G}+10.7 \text { and } F r_{G} \\
>0.04
\end{aligned}
$$

651

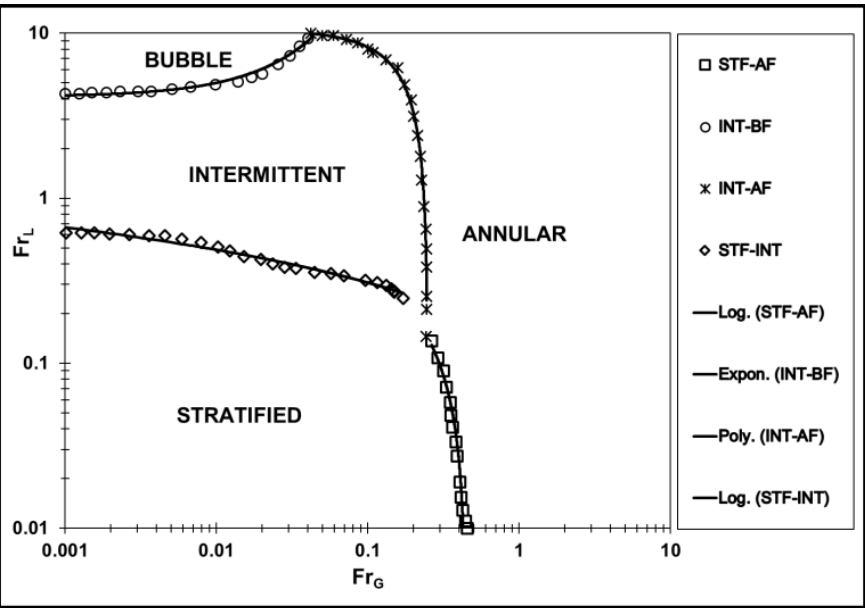

Figure 12: Developed flow regime boundaries from database

Presented in Fig. 12 is the flow regime map developed from this study, which can be employed for both horizontal and eccentric annulus geometries. Flow regimes can be determined step by step based on the liquid and gas Froude numbers as illustrated in the flow chart shown in Fig. 13.

The developed parameters were tested against 109 data points from the concentric annulus of this study, predicting the flow regimes with an accuracy of $90 \%, 81 \%$ and $85 \%$ respectively for the Bubble, Intermittent and Annular flow regimes respectively. The breakdown of the performance of transition parameters on 
663 the different flow regime data used to test are presented on Table 664 1. It should be noted that these parameters should be applied to 665 annulus with hydraulic diameter less than $0.089 \mathrm{~m}$. Further 666 testing of the transition parameters could be carried out as more 667 experimental data becomes available to confirm the accuracy of 668 these parameters. Also these parameters may require 669 modification if they are to be extended to liquid phase having 670 viscosity above $0.22 \mathrm{~kg} / \mathrm{ms}$.

Table 1: Performance of transition parameters on test data set.

\begin{tabular}{cccc}
\hline Flow Regimes & $\begin{array}{c}\text { Number } \\
\text { of data } \\
\text { points }\end{array}$ & $\begin{array}{c}\text { Accurately } \\
\text { classified } \\
\text { based on } \\
\text { transition } \\
\text { parameters }\end{array}$ & $\begin{array}{c}\text { Misclassified } \\
\text { based on } \\
\text { transition } \\
\text { parameters }\end{array}$ \\
\hline Bubble Flow & 10 & 9 & 1 \\
Intermittent & 59 & 48 & 11 \\
Flow & & & \\
Annular Flow & 40 & 34 & 6 \\
\hline
\end{tabular}

\section{Conclusion}

Two-phase air-water flow regimes were characterized for horizontal annular conduits in this study. Experimental studies were carried out in a $10.8 \mathrm{~m}$ long annulus section with outer diameter of $0.0768 \mathrm{~m}$ and inner diameter of $0.060 \mathrm{~m}$ and two eccentricity positions (concentric and fully eccentric). The range of superficial velocities of air and water were $0.16-24 \mathrm{~m} / \mathrm{s}$ and $0.15-2.78 \mathrm{~m} / \mathrm{s}$ respectively. Observed flow regimes in both annulus setups were dispersed bubble, elongated bubble, slug, wavy slug, churn, wavy annular and annular flow regimes. The results of this study can be summarised as follows:

(1) A new flow regime is classified in this study as wavy slug flow. It is characterized as such because it is observed to have different features than the conventionally observed slug or wavy flow regimes.

(2) The annulus eccentricity is observed to affect the observed flow regimes at low air and lowest water superficial velocities investigated in this study; where elongated bubble flow is encountered in the concentric annulus and slug flow in the fully eccentric annulus

(3) The bubble shape observed in the elongated bubble flow regime and the liquid film height during the wavy annular and annular flow regimes are affected by annulus eccentricity, visually observed difference were also confirmed from statistical PDF trends.

(4) The flow regime transitions observed to take place at higher liquid superficial velocities and lower gas

\section{Acknowledgment}

Edem Nsefik Eyo wishes to acknowledge The Petroleum Technology Development Fund of Nigeria (PTDF) for funding this research.

\section{References}

Barnea, D., Shoham, O. and Taitel, Y. (1980) 'Flow pattern characterization in two phase flow by electrical conductance probe', Int. J. Multiphase Flow, 6(5), pp. 387-397. doi: 10.1016/0301-9322(80)90001-4.
713

superficial velocities in the fully eccentric annulus when compared to the concentric one.

(5) Flow regime transition criteria available in literature for two-phase flow in pipes and horizontal annulus could not accurately predict experimental data.

(6) The developed flow regime transitions parameters covers a wider range of flow properties, fluid properties and conduit properties than other such attempts available in literature. Also the proposed flow regime map can be used successfully to determine two-phase flow regimes in horizontal annuli.

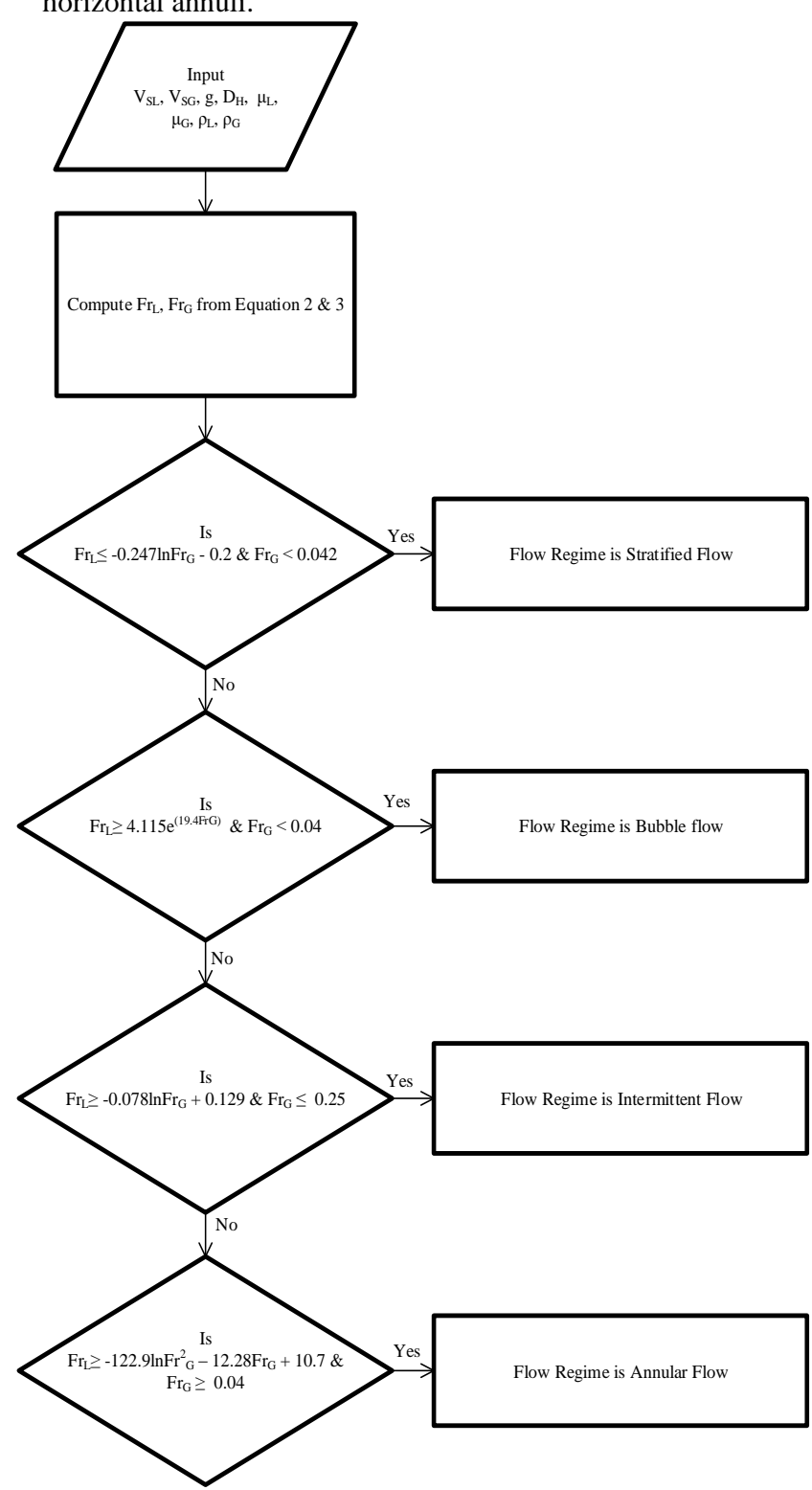

Figure 13: Flow chart for flow regime identification in horizontal annuli.

Das, G., Das, P. K., Purohit, N. K. and Mitra, a. K. (1999) 'Flow Pattern Transition During Gas Liquid Upflow Through Vertical Concentric Annuli-Part II: Mechanistic Models', Journal of Fluids Engineering, 121(4), p. 902. doi: 10.1115/1.2823553. Ekberg, N. P., Ghiaasiaan, S. M., Abdel-Khalik, S. I., Yoda, M. and Jeter, S. M. (1999) 'Gas - liquid two-phase flow in narrow horizontal annuli’, Nuclear Engineering and Design, 192(1), pp. 59-80. doi: 10.1016/S0029-5493(99)00078-3.

Fan, S. and Yan, T. (2014) 'Two-phase air-water slug flow measurement in horizontal pipe using conductance probes and neural network', IEEE Transactions on Instrumentation and Measurement, 63(2), pp. 456-466. doi: 10.1109/TIM.2013.2280485. Fossa, M. (1998) 'Design and performance of a conductance 
probe for measuring the liquid fraction in two-phase gas-liquid flows', Flow Measurement and Instrumentation, 9(2), pp. 103 109. doi: 10.1016/S0955-5986(98)00011-9.

Gschnaidtner, T. (2013) Two-Phase Flow (Air-Water)

Characteristics in Annulus. Cranfiled University, Bedfordshire UK.

Hewitt, G.F. and ,Jayanti, S. (1993) 'To churn or not to churn', Int. J. Multiphase Flow, 19(3) pp: 527-529.

Kelessidis, V. C. and Dukler, A. E. (1989) 'Modeling flow pattern transitions for upward gas-liquid flow in vertical concentric and eccentric annuli', Int. J. Multiphase Flow, 15(2), pp. 173-191.

Lage, A. C. V. M., Rommetveit, R., Time, R. W. and College, S. (2000) 'An Experimental and Theoretical Study of Two-Phase Flow in Horizontal or Slightly Deviated Fully Eccentric Annuli'. Mendes, F. A. ., Rodriguez, O. M. ., Estevam, V. and Lopes, D. (2011) 'Flow Patterns in inclined gas-liquid annular duct flow', WIT Transactions on Engineering Sciences, 70, pp. 271-283. doi: 10.2495/MPF110.

Metin, C. O. and Ozbayoglu, M. . (2007) 'Two-Phase Fluid Flow through Fully Eccentric Horizontal Annuli: A Mechanistic Approach', in SPE/ICoTA Coiled Tubing and Well Intervention Conference and Exhibition. Texas, pp. 1-7.

Nossen, J., Liu, L., Skjaeraasen, O., Tutkun, M., Amundsen, J. E., Sleipnaes, Popovici, N., Hald, K., Langsholt, M. and Ibarra, R. (2017) 'An experimental study of two-phase in horizontal and inclined annuli', in HBR Cannes. Cannes, France, pp. 87-102. Omurlu, C. and Ozbayoglu, E. M. (2006) 'A New Mechanistic Model For Two-Phase Flow Through Eccentric Horizontal Annulus', SPE Europe/EAGE Annual Conference and Exhibition. Vienna,Austria, (June), pp. 1-7. doi: 10.2523/100300-MS. Osamusali, S. . and Chang, J. . (1988) 'Two phase flow regime transition in a horizontal pipe and annulus flow under gas-liquid two-phase flow', ASME Fundamentals of Gas-Liquid Flows, FED-72, pp. 63-69.

Osgouei, R. E. and Ozbayoglu, E. M. (2010) 'Flow Pattern Identification of Gas-Liquid Flow Through Horizontal Annular Geometries', in SPE Oil and Gas India Conference and Exhibition, pp. 1-9.

Osgouei, R. E., Ozbayoglu, M. ., Ozbayoglu, M. and Yuksel, E. H. (2013) 'The Determination of Two Phase Liquid-Gas Flow Behavior through Horizontal Eccentric Annular Geometry by Modification of Beggs \& Brill and Lockhart \& Martinelli Models', in Proceedings of the ASME 2013 Fluids Engineering Division Summer Meeting. Nevada: ASME, pp. 1-9. Available at: http://proceedings.asmedigitalcollection.asme.org.

Osgouei, R. E., Ozbayoglu, M. E. and Ozbayoglu, A. M. (2012) 'A Mechanistic Model to Characterize the Two Phase Drilling Fluid Flow through Inclined Eccentric Annular Geometry', in SPE Oil and Gas India Conference and Exhibition. Mumbai, India.

Ozbayoglu, M. E. and Omurlu, C. (2007) 'Modelling of twophase flow through concentric annuli', Petroleum Science and Technology, 25(8), pp. 1027-1040. doi: $10.1080 / 10916460600695132$.

Salcudean, M., Groeneveld, D. and Leung, L. (1983) 'Effect of Flow-Obstruction Geometry on Pressure Drops in Horizontal Air-Water Flow', Int. J. Multiphase Flow, 9(I), pp. 73-85. Sunthankar, A. A., Miska, S., Kuru, E. and Kamp, A. (2000) 'New Developments in Aerated Mud Hydraulics for Horizontal Well Drilling', SPE Journal, 9(01), pp. 5-12. doi: 10.2118/87675-PA.

Yadigaroglu, G., Banerjee, S. and Hewitt, G. F. (2018) Introduction to Multiphase Flow. Springer International Publishing. doi: 10.1007/978-3-319-58718-9.

Zhou, L., Ahmed, R. M., Miska, S. Z., Takach, N. E., Yu, M. and Pickell, M. B. (2004) 'Experimental Study of Aerated Mud Flows under Horizontal Borehole Conditions', Proceedings of SPE/ICoTA Coiled Tubing Conference and Exhibition, (March), pp. 23-24. doi: 10.2118/89531-MS. 